\title{
CLEAR CELL CARCINOMA WITH COEXISTENT SMALL MUCINOUS TUMOR COMPONENT ARISING FROM EXTRAGONADAL ENDOMETRIOTIC CYST
}

Shankar Annapoorni ${ }^{1}$, Aravinth Subramaniam²

\section{HOW TO CITE THIS ARTICLE:}

Shankar Annapoorni, Aravinth Subramaniam. "Clear Cell Carcinoma with Coexistent Small Mucinous Tumor Component Arising from Extragonadal Endometriotic Cyst". Journal of Evolution of Medical and Dental Sciences 2015; Vol. 4, Issue 51, June 25; Page: 8938-8943, D0I: 10.14260/jemds/2015/1295

\begin{abstract}
The occurrence of clear cell carcinoma in extra gonadal endometriotic cyst is well documented in literature. We report a rare case of malignant tumor identified in the mural nodule of a cystic mass. The cyst was located in the retroperitoneum, posterior to caecum. The tumor had an unusual histomorphologic appearance with co-existent minor benign mucinous tumor component. Rare clinical presentation with unfamiliar histomorphological appearance of this tumor makes it worthy of reporting.
\end{abstract}

KEYWORDS: Clear cell carcinoma, Extragonadal Endometriotic cyst.

INTRODUCTION: Endometriosis is associated with increased risk for the development of ovarian carcinoma. The common tumor subtypes which co-exist with endometriosis are clear cell carcinoma followed by endometrioid carcinoma and less commonly serous and mucinous types.(1) Of all the tumor types, clear cell carcinoma is more frequently associated with endometriosis.(2) Clear cell carcinoma arising in an extraovarian endometriosis has also been described in sigmoid colon and cesarean section scars. The carcinogenetic pathways, involved in the development of malignancy from endometriosis include oxidative stress, inflammation and hyperestrogenism.(3) Various histopathological entities described in literature including atypical endometriosis, adenofibromatous and cystadenofibromatous tumors represent intermediate stages in the neoplastic transformation of endometriosis.(4) It is not only essential to identify these tumors at their early stage of development but also important to distinguish between various tumor subtypes. Determining the stage of tumor, their sub types and nuclear grade are important for deciding appropriate management protocol and prognostication. In this article, we report a rare case of clear cell carcinoma in an endometriotic cyst and also intend to discuss all the possible histomorphological variations that can exist in this scenario.

CASE PRESENTATION: 47year old women presented with complaints of pain in the right iliac region, which lasted for one week. She underwent hysterectomy 1 year before she presented with the current problem. CT done at the time of hysterectomy showed a cystic mass measuring $4.5 \mathrm{cms}$ in diameter in the retroperitoneum posterior to the caecum. Repetition of CT for the present problem revealed the persistence of the cyst in the same location but with slight increase in size and the presence of a mural nodule within it measuring $3 \times 1.5 \mathrm{cms}$ in maximum dimension. The other abdominal organs were normal. Blood - investigations revealed no increase in serum CA19.9, AFP or Beta- HCG. The appearance of mural nodule in a cystic mass aroused the suspicion of malignancy. There was no evidence of any pelvic lymph node enlargement and no obvious primary was detected after thorough radiological workup. Hence complete excision of cyst by laparoscopy was performed. Gross examination of the cyst, which measured $10 \times 8 \times 7 \mathrm{cms}$, had smooth external surface and on cut 
section showed a unilocular cystic cavity containing hemorrhagic material. There was a solid nodular intraluminal projection measuring $3 \times 2 \mathrm{cms}$ in maximum dimension with soft cut surface.

DISCUSSION: The potential of an ectopic endometriotic cyst to transform into malignancy was first reported by Sampson.(5) The three criteria that were proposed to be used for confirming endometrial origin of tumor are the following, (a) Histopathologic documentation of endometriosis. (b) Histopathologic type of neoplasm compatible with endometriotic origin. (C) None of primary tumor identified in the patient.(6)

The diagnosis of endometriosis in our case was based on histomorphological appearance supported by immunohistochemical finding of CD10 Positive stromal cells.

The fact that the nodular solid area constituted only $1 \%$ of cystic mass helped in inferring that malignancy was in its early stage of development. Microscopic evaluation of the cyst showed neoplastic cells arranged in tubulocystic pattern in the nodular area and the rest of cyst wall showed glandular structures lined by low cuboidal clear cells separated by CD10 Positive stromal cells. The nodular neoplastic component in the backdrop of endometriotic cyst, hints at the probable transformation of endometriotic cyst into malignancy. In a study of 115 women with endometriosis associated ovarian and extra ovarian malignancies, the most common type was clear cell and endometrioid type comprising of $23 \%$. The mixed epithelial pattern was identified in 19\%.(7)

Clear cell carcinoma was the most likely possibility in our case, taking into consideration the clinical context. The neoplastic cells in our case had clear to pale eosinophilic cytoplasm and mildly enlarged hyperchromatic nuclei. Although, the nuclear/cytoplasm ratio was increased in our case, it was not significant enough to be placed in serous category. Complex architectural pattern with invasion reflected the malignant nature of the tumor. Presence of eosinophilic hyaline globules, which are more frequently described in clear cell variety, served as additional supportive evidence in favour of clear cell carcinoma. Hyaline globules are also known to be commonly present in mixed mullerian type next to clear cell carcinoma compared with other gynecologic malignancies.(8) The tumor types that needed to be excluded in our case were serous and mucinous types. Clinical presentation of tumor was that of an early stage, while the nuclear cytomorphology and architectural arrangement corresponded to WHO Grade II. Hence the differential diagnosis from Histopathologic viewpoint was (i) High grade serous/mucinous and (ii) mixed type. The points that excluded the serous type are the absence of branching complex papillae with tufting, obvious destructive stromal invasion, stratification of epithelium and high N/C ratio.(9) Also the degree of nuclear pleomorphism tends to be greater in serous carcinoma than what is observed in our case.(10) The proliferative index of serous carcinoma is high, but the KI67 index in our case was 5\%. Immunohistochemical evaluation is useful in distinguishing between Nonmucinous, mucinous and metastatic tumors.(11) The markers usually expressed by clear cell variants are CK7, Cam5.2, Vimentin, BCL2 CA125 and Polyclonal CEA. Clear cell carcinomas usually do not express CK20 and WT1.(12)

The IHC results in our case, showed diffuse positivity for CK7, EMA, CEA and Negativity for CK20. The observed findings in this case further strengthened evidence in favour of clear cell type and helped in excluding mucinous tumor. Mixed epithelial carcinoma with ambiguous morphology is another diagnostic consideration in the present case due to the presence of small portion of mucinous epithelial cell component constituting less than $10 \%$ of total tumor volume. The small percentage of this mucinous component with low grade nuclear features does not satisfy the definition of mixed epithelial tumor(13) and hence could not be placed in this category. According to 
the theory of secondary mullerian system in the pathogenesis of endometriosis by Lauchlan.(14) (1972), the mesothelial covering of the pelvic peritoneum and ovarian surface can transform into varied histologic types of tumors including low grade serous, mucinous and their malignant counterparts. The detection of clear cell carcinoma in extraovarian pelvic location in our case can be explained by this theory. In the present case the ambiguous morphology and the presence of benign mucinous type epithelium as a minor element could represent intermediate morphologic forms in the carcinogenetic pathway of extraovarian endometriosis. Association of ovarian clear cell carcinoma with mucinous tumor is also documented in literature previously supporting this theory.(15)

The management of clear cell carcinoma irrespective of ovarian/extra ovarian tumor depends majorly on the stage of tumor. Data from literature suggest that early stage disease (FIGO stage 1A or IC) do well with surgery alone.(16) In the present case, only surgical excision was done and was not followed with adjuvant chemotherapy. The patient is doing well 11 months after surgery.

CONCLUSION: Malignant transformation of extragonadal endometriotic cysts is very rare. Malignancy arising from endometriotic cysts can present with varied morphological appearance, which represents intermediate forms in their carcinogenetic pathways. Identifying the proper subtype, assigning appropriate grade and stage, forms a vital part of workup in the optimal management of these tumors.

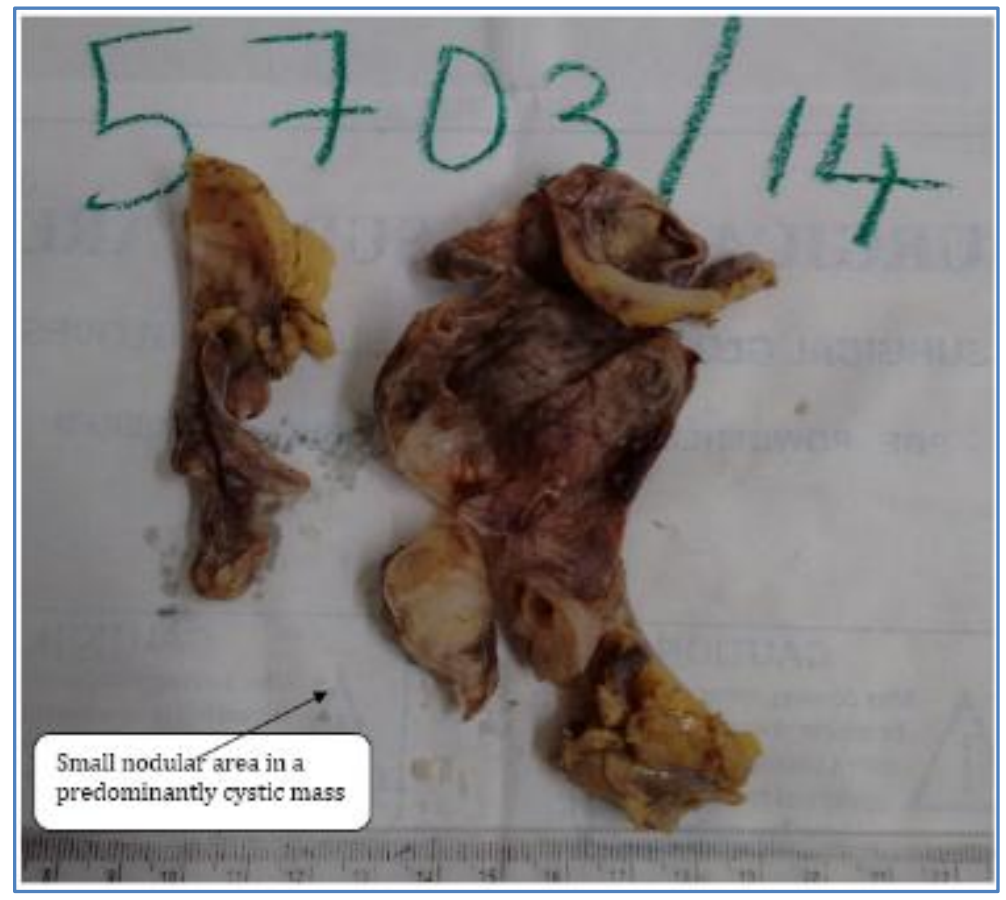

Fig. 1 


\section{CASE REPORT}

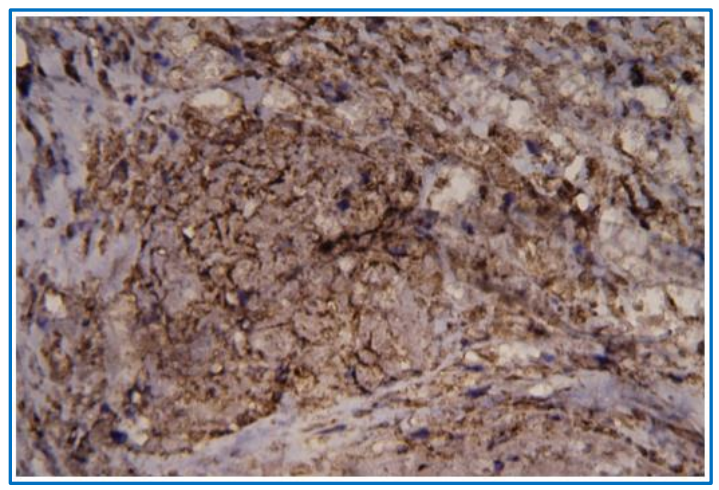

Fig. 2: Clear cell carcinoma CD 10 positive stromal cells

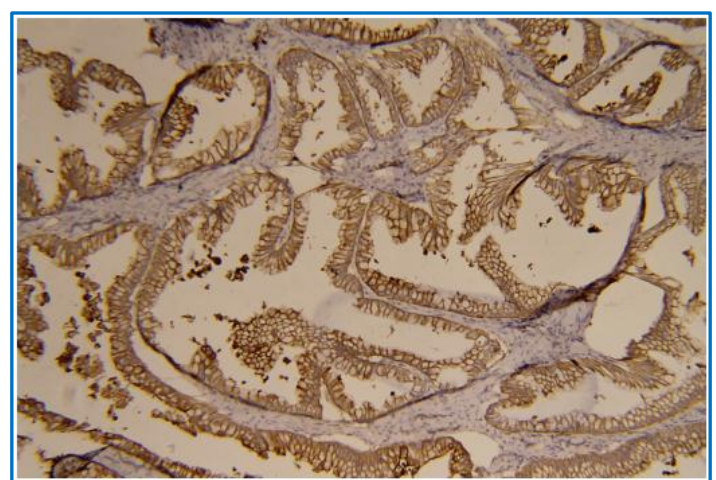

Fig. 3: CEA positive neoplastic cells

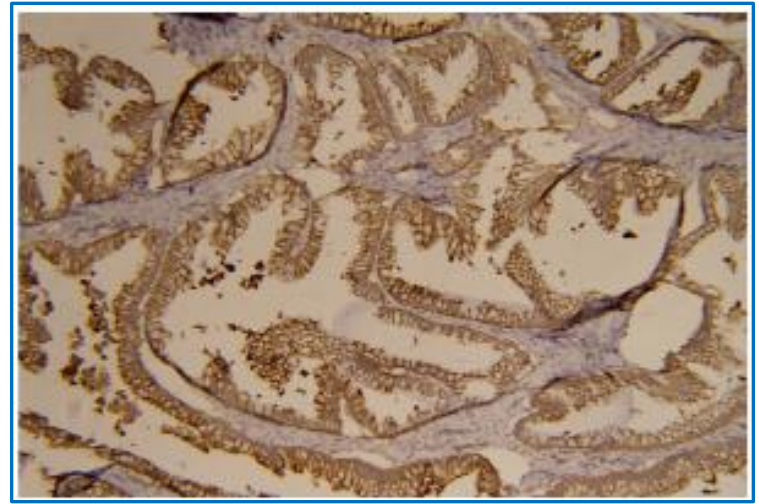

Fig. 4: CK 7 positive neoplastic cells

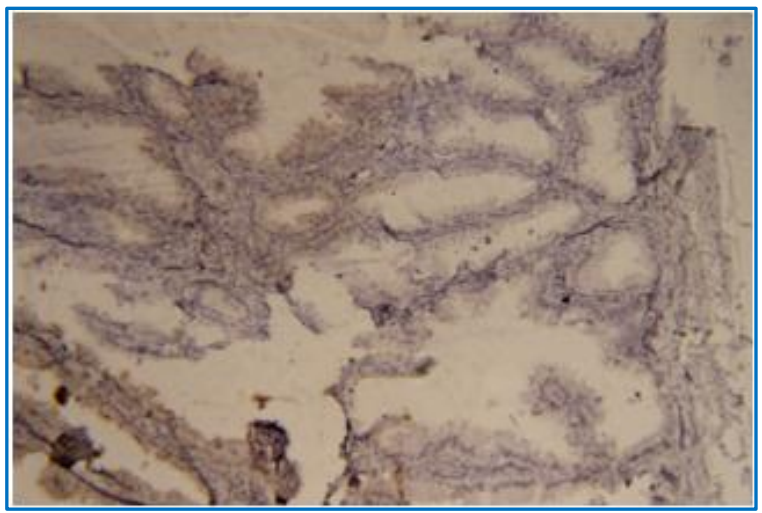

Fig. 5: CK 20 negative neoplastic cells

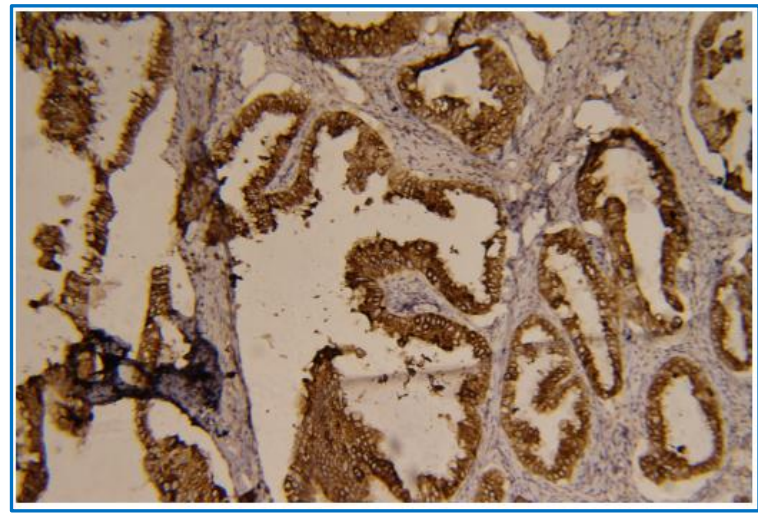

Fig. 6: EMA positive neoplastic cells

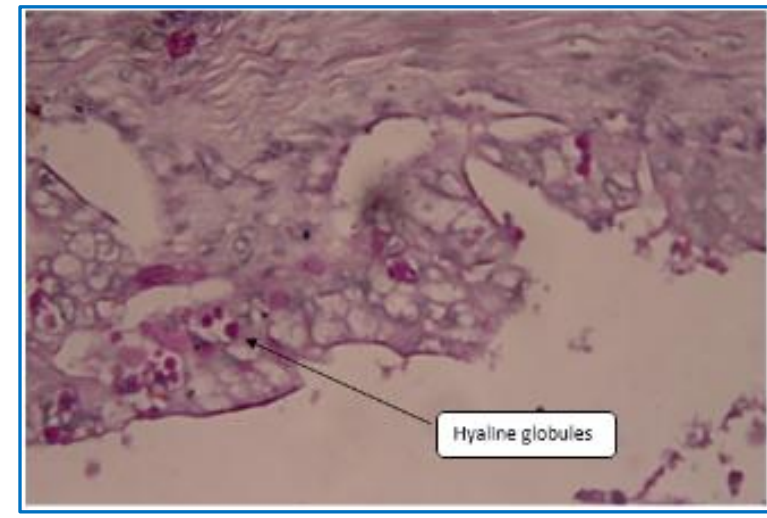

Fig. 7: Hyaline globules in neoplastic cells 


\section{CASE REPORT}

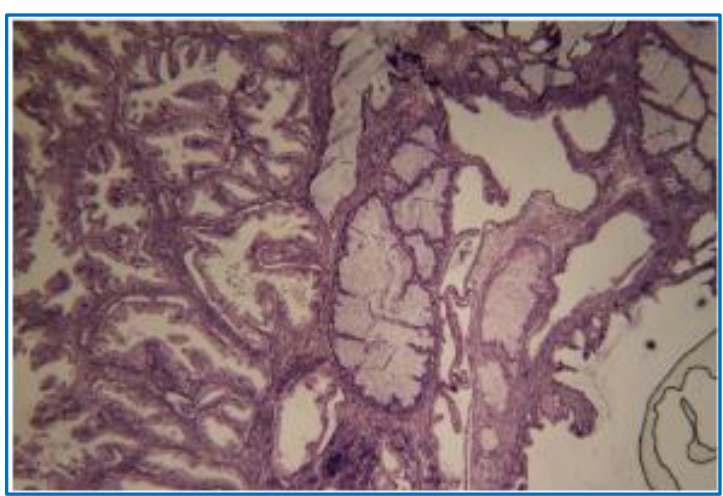

Fig. 8: Clear cell carcinoma with mucinous elements

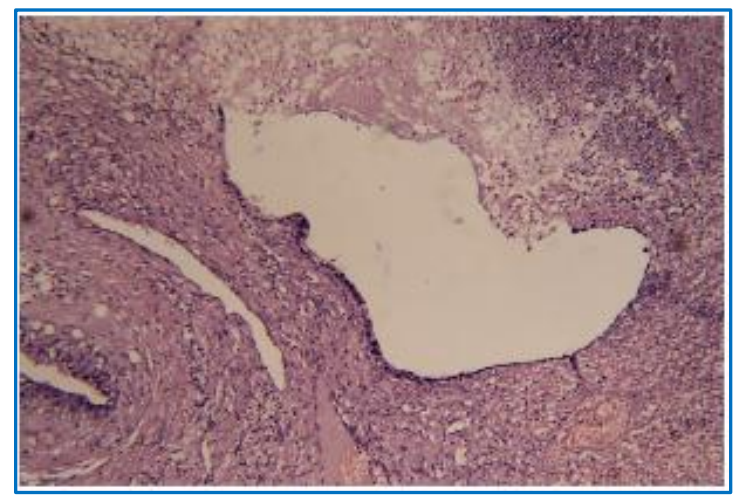

Fig. 9: Endometriotic Foci in clear cell carcinoma

\section{REFERENCES:}

1. Boyraz G, Selcuk I, Yazicioglu A, Tuncer ZS. Ovarian carcinoma associated with endometriosis. European journal of obstetrics, gynecology, and reproductive biology. 2013; 170(1): 211-3.

2. Yamamoto S, Tsuda H, Yoshikawa T, Kudoh K, Kita T, Furuya K, et al. Clear cell adenocarcinoma associated with clear cell adenofibromatous components: a subgroup of ovarian clear cell adenocarcinoma with distinct clinicopathologic characteristics. The American journal of surgical pathology. 2007; 31(7): 999-1006.

3. Worley MJ, Welch WR, Berkowitz RS, Ng SW. Endometriosis-associated ovarian cancer: a review of pathogenesis. International journal of molecular sciences. 2013; 14(3): 5367-79.

4. Bell DA, Scully RE. Benign and borderline clear cell adenofibromas of the ovary. Cancer. 1985; 56(12): 2922-31.

5. Sampson.J.A. Endometrial carcinoma of ovary arising in endometrial tissue in the organ, Arch, surg 10, 1(1925). Arch, surg 1925; 10(1).

6. Hitti IF, Glasberg SS, Lubicz S. Clear cell carcinoma arising in extraovarian endometriosis: report of three cases and review of the literature. Gynecologic oncology. 1990; 39(3): 314-20.

7. Modesitt SC, Tortolero-Luna G, Robinson JB, Gershenson DM, Wolf JK. Ovarian and extraovarian endometriosis-associated cancer. Obstetrics and gynecology. 2002; 100(4): 788-95.

8. Al-Nafussi AI, Hughes DE, Williams AR. Hyaline globules in ovarian tumours. Histopathology. 1993; 23(6): 563-6.

9. Vang R, Shih Ie M, Kurman RJ. Ovarian low-grade and high-grade serous carcinoma: pathogenesis, clinicopathologic and molecular biologic features, and diagnostic problems. Advances in anatomic pathology. 2009; 16(5): 267-82.

10. Chiang S, Soslow RA. Updates in diagnostic immunohistochemistry in endometrial carcinoma. Seminars in diagnostic pathology. 2014; 31(3): 205-15.

11. Vang R, Whitaker BP, Farhood AI, Silva EG, Ro JY, Deavers MT. Immunohistochemical analysis of clear cell carcinoma of the gynecologic tract. International journal of gynecological pathology: official journal of the International Society of Gynecological Pathologists. 2001; 20(3): 252-9.

12. McCluggage WG, Young RH. Immunohistochemistry as a diagnostic aid in the evaluation of ovarian tumors. Seminars in diagnostic pathology. 2005; 22(1): 3-32. 


\section{CASE REPORT}

13. World Health Organization Classification of tumors. Pathology and Genetics of tumors of the breast and female genital organs. [press release]. Lyon: IARC press2003.

14. Lauchlan SC. The secondary Mullerian system. Obstetrical \& gynecological survey. 1972; 27(3): 133-46.

15. Dutt N, Berney DM. Clear cell carcinoma of the ovary arising in a mucinous cystadenoma. Journal of clinical pathology. 2000; 53(12): 938-9.

16. Hoskins PJ, Le N, Gilks B, Tinker A, Santos J, Wong F, et al. Low-stage ovarian clear cell carcinoma: population-based outcomes in British Columbia, Canada, with evidence for a survival benefit as a result of irradiation. Journal of clinical oncology: official journal of the American Society of Clinical Oncology. 2012; 30(14): 1656-62.

\section{AUTHORS:}

1. Shankar Annapoorni

2. Aravinth Subramaniam

PARTICULARS OF CONTRIBUTORS:

1. Senior Consultant Pathologist, Department of Pathology, GEM Hospital, Coimbatore.

2. Consultant Pathologist, Department of Pathology, GEM Hospital, Coimbatore.

FINANCIAL OR OTHER

COMPETING INTERESTS: None

\section{NAME ADDRESS EMAIL ID OF THE} CORRESPONDING AUTHOR:

Dr. Shankar Annapoorni, FF2, Block C, Swapnalok,

Parsn Apartments,

Nanjundapuram Road,

Coimbatore-641036.

E-mail: shankar.annapoorni@gmail.com

Date of Submission: 17/04/2015.

Date of Peer Review: 20/04/2015.

Date of Acceptance: 17/06/2015.

Date of Publishing: 25/06/2015. 